\title{
BMJ Open Incidence, risk factors and risk prediction of hospital-acquired suspected adverse drug reactions: a prospective cohort of Ugandan inpatients
}

\author{
Ronald Kiguba, ${ }^{1}$ Charles Karamagi, ${ }^{2}$ Sheila M Bird ${ }^{3}$
}

To cite: Kiguba $R$, Karamagi C, Bird SM. Incidence, risk factors and risk prediction of hospitalacquired suspected adverse drug reactions: a prospective cohort of Ugandan inpatients. BMJ Open 2017;7:e010568. doi:10.1136/bmjopen-2015010568

- Prepublication history and additional material is available. To view please visit the journal (http://dx.doi.org/ 10.1136/bmjopen-2015010568).

Received 17 November 2015 Revised 12 April 2016 Accepted 14 June 2016

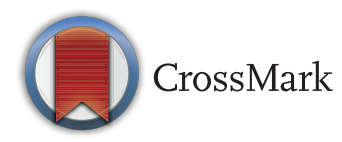

\footnotetext{
${ }^{1}$ Department of Pharmacology and Therapeutics, Makerere University College of Health Sciences, Kampala, Uganda ${ }^{2}$ Clinical Epidemiology Unit, Makerere University College of Health Sciences, Kampala, Uganda

${ }^{3}$ Medical Research Council Biostatistics Unit, Cambridge, UK
}

Correspondence to Ronald Kiguba;

kiguba@gmail.com

\section{ABSTRACT}

Objectives: To determine the incidence and risk factors of hospital-acquired suspected adverse drug reactions (ADRs) among Ugandan inpatients. We also constructed risk scores to predict and qualitatively assess for peculiarities between low-risk and high-risk ADR patients.

Methods: Prospective cohort of consented adults admitted on medical and gynaecological wards of the 1790-bed Mulago National Referral Hospital. Hospitalacquired suspected ADRs were dichotomised as possible (possible/probable/definite) or not and probable (probable/definite) or not, using the Naranjo scale. Risk scores were generated from coefficients of ADR risk-factor logistic regression models.

Results: The incidence of possible hospital-acquired suspected ADRs was $25 \%$ (194/762, $95 \% \mathrm{Cl}: 22 \%$ to 29\%): 44\% (85/194) experienced serious possible ADRs. The risk of probable ADRs was $11 \%(87 / 762$, $95 \%$ Cl $9 \%$ to $14 \%): 46 \%$ (40/87) had serious probable ADRs. Antibacterials-only (51/194), uterotonics-only (21/194), cardiovascular drugs-only (16/194), antimalarials-only (12/194) and analgesicsonly $(10 / 194)$ were the most frequently implicated. Treatment with six or more conventional medicines during hospitalisation $(\mathrm{OR}=2.31,95 \% \mathrm{Cl} 1.29$ to 4.15$)$ and self-reported herbal medicine use during the 4 weeks preadmission $(\mathrm{OR}=1.96,95 \% \mathrm{Cl} 1.22$ to 3.13) were the risk factors for probable hospitalacquired ADRs. Risk factors for possible hospitalacquired ADRs were: treatment with six or more conventional medicines $(\mathrm{OR}=2.72,95 \% \mathrm{Cl} 1.79$ to 4.13), herbal medicine use during the 4 weeks preadmission ( $\mathrm{OR}=1.68,95 \% \mathrm{Cl} 1.16$ to 2.43 ), prior 3 months hospitalisation $(\mathrm{OR}=1.57,95 \% \mathrm{Cl} 1.09$ to 2.26) and being on gynaecological ward $(\mathrm{OR}=2.16$, $95 \% \mathrm{Cl} 1.36$ to 3.44). More drug classes were implicated among high-risk ADR-patients, with cardiovascular drugs being the most frequently linked to possible ADRs.

Conclusions: The risk of hospital-acquired suspected ADRs was higher with preadmission herbal medicine use and treatment with six or more conventional medicines during hospitalisation. Our risk scores

\section{Strengths and limitations of this study}

- A pilot was conducted to assess the feasibility of the cohort and to refine study tools.

- Medical and gynaecological inpatients were recruited and followed-up.

- The need to collect high-quality data limited the number of inpatients studied to 762 .

- Clinical examination was the main method used to identify suspected adverse drug reactions due to limitations in timely availability of laboratory investigation results.

should be validated in large-scale studies and tested in routine clinical care.

\section{BACKGROUND}

Adverse drug reactions (ADRs) are ranked the fourth and seventh leading cause of death in the USA and Sweden, respectively. ${ }^{12}$ A cohort of 3322 inpatients in the UK showed a $16 \%$ incidence of hospital-acquired ADRs, but a German study of 907 inpatients with a large amount of laboratory data and parameters of vital status at baseline reported an ADR incidence of $38 \% .{ }^{3}{ }^{4}$ A recent systematic review of European inpatients, including 13 studies, reported a $10.1 \%$ median percentage incidence of hospital-acquired ADRs. ${ }^{5}$ However, a lower incidence $(6 \%)$ of ADRs was reported in a South African cohort of 665 medical inpatients. ${ }^{6}$

Known risk factors for ADRs include patient-related (age, gender, genetic makeup and pregnancy), drug-related (number of administered conventional medicines, drug class's toxicity profile, eg, antiretroviral therapy (ART) and drug dose), diseaserelated (eg, comorbidities, chronic/acute 
condition) and social (alcoholism, smoking, use of alternative/herbal medicines-hereafter herbal medicines) characteristics. ${ }^{4}{ }^{7-9}$ The ADR risk factors for a patient population can be used to create ADR risk-prediction models for use in routine clinical practice to identify at-risk patients for ADRs. ${ }^{10}{ }^{11} \mathrm{~A}$ good risk-prediction model should undergo four stages, namely development (to identify risk factors for designing the model) and validation (test model performance) in the first instance, and subsequently, impact (usefulness in routine clinical practice) and implementation (acceptance for use in clinical practice) assessment. ${ }^{11}$ However, little is known about the incidence of hospital-acquired $\mathrm{ADRs}^{6}$ and their risk factors among inpatients in sub-Saharan Africa, particularly in Uganda, which the present study aimed to determine. We also sought to describe the characteristics of the hospital-acquired suspected ADRs and identify the commonly implicated drug classes; and to construct ADR risk-prediction models for possible/probable ADRs to differentiate between low-risk and high-risk ADR-patients, particularly on characteristics not used to compute the risk scores.

\section{METHODS}

\section{Study design and setting}

This prospective cohort study was conducted among adult hospitalised patients ( $\geq 18$ years) at the 1790-bed Mulago National Referral Hospital with at least 140000 inpatients annually. Details of the study setting, cohort design, data collection and data management have been described elsewhere. ${ }^{12}$ Briefly, three medical wards: Infectious Diseases and Gastrointestinal Illnesses (IDGI); Haematology, Neurology and Endocrinology (HNE); and Cardiovascular, Pulmonology and Nephrology (CPN); and one Gynaecological ward (GYN) constituted our study setting. Each ward has an official bed capacity of 54 but can receive up to 80 inpatients. Total daily admissions on each of the IDGI and CPN medical wards average 10-15 patients and 5-10 patients in HNE, thus 25-40 medical ward admissions per day. The GYN ward admits 20-25 patients per day.

\section{Data collection}

During October to November 2013, a pilot study was conducted on the wards to assess the feasibility of the main cohort and to pretest the study tools. Data obtained from the pilot study, however, are not included in the final analyses. The main study started in December 2013 to April 2014 when research teams recruited and followed-up inpatients on the study wards using a systematic random sampling procedure whereby three new admissions per day on long-stay wards (HNE/ CPN) and six per day on short-stay wards (IDGI/GYN) were to be recruited. Each ward-team purposed to select at random one of the first two (IDGI), three (HNE) and four (CPN/GYN) new admissions, and there after every second, third and fourth admission, respectively.
Four research teams collected the data from inpatients who had voluntarily given written informed consent. Each team comprised a medical doctor, pharmacist and degree nurse. Prior to data collection, the data collectors received week-long training on the practical pharmacovigilance aspects of the study including how to detect suspected ADRs using trigger tools. The principal author conducted daily reviews of study procedures to ensure adherence to the study protocol. A gynaecologist/obstetrician and an internist, both staff of Mulago Hospital based on the gynaecological and medical wards, respectively, were the study physicians who resolved any clinical problems encountered by the data collection teams, while the senior clinical pharmacist (principal author) resolved pharmacological issues.

Each research team conducted the baseline patient assessment to obtain relevant data on demographics, clinical conditions and medications used and thereafter conducted daily assessments until discharge, transfer, death or loss to follow-up. In each research team, clinical data related to suspected ADRs were captured from clinical notes in the patient's file, from clinical examination of the patient by each team's medical officer and by patient/caregiver/ward staff interviews. Each research team's pharmacist interviewed the patient at recruitment or used the patient's available medical documents to obtain baseline information on any medications used in the 4 weeks preceding hospitalisation. Medication data were obtained from the patient's clinical notes, treatment sheets, drug administration charts, dispensing records of ward pharmacies, pill count validation of a patient's oral medication (tablets, capsules) and by viewing of unused injectable medicines in the possession of the patient/caretaker; and by daily interviews with the patient/caregiver or ward staff to elicit further information on clinical signs and symptoms not documented in the patient's records. Research teams collected data daily from 08:00 to 18:00 from Monday to Friday and from 10:00 to 18:00 on weekends and public holidays.

\section{Data management}

We used Epidata V.3.1 software for data entry and applied check programmes to limit out-of-range data entry errors. To verify the quality of data abstraction and entry, $10 \%$ of the 762 case report forms (CRFs) were randomly re-sampled using Stata V.12.0 (StataCorp. Stata Statistical Software: Release 12. College Station, Texas: StataCorp LP; 2011) to generate 76 cases for whom previously abstracted data were re-abstracted by RK and re-entered into the Epidata V.3.1 databank by a pretrained data entry clerk. Double-data entry verification was used to identify and record discrepancies between previously entered data against data capture at the re-entry phase. Where data discrepancies occurred, the original CRF was cross-checked and the error corrected. If the estimated discrepancy rate did not exclude a $10 \%$ data entry error-rate as the upper $95 \%$ confidence limit, the principal author re-checked all 762 original records 
for all important such fields, which included number of possible suspected ADRs.

\section{Identification of suspected ADRs}

We defined suspected ADRs according to the WHO definition. ${ }^{13} 14$ Operationally, a suspected $A D R$ was any undesirable medical occurrence that developed after the administration of a drug and for which there was, at least, a possible causal relationship between the drug and the event as measured by the Naranjo ADR Probability Scale. ${ }^{15}{ }^{16}$ Possible ADRs included possible, probable and definite ADRs while probable ADRs represented probable and definite ADRs only and were dichotomised to possible ADR or not and, separately, to probable ADR or not. Preventable and non-preventable suspected ADRs, as measured by the modified Schumock and Thornton Preventability Scale, ${ }^{17}{ }^{18}$ were evaluated. Severity was assessed using the Division of AIDS Table for Grading the Severity of Adult and Paediatric Adverse Events ${ }^{19}$ and seriousness according to the WHO Uppsala Monitoring Centre (UMC) criteria. $^{20}$ Clinical examination was the main method used to identify suspected ADRs. To increase the probability to detect suspected ADRs, patients were screened using an ADR trigger tool. ${ }^{21}$ Consensus agreement on ADR causality, preventability, severity and seriousness was reached in a committee headed by the ward-based study physician and senior clinical pharmacist (principal author). We used the team approach, other than individual assessments followed by comparison of interobserver agreement, to reflect the routine on-ward practice for solving clinical problems whereby nurses, medical doctors and clinical pharmacists brainstorm on patients' clinical problems and consult relevant literature before arriving at clinical decisions.

\section{STATISTICAL ANALYSIS}

Sample size estimation

With a presumed incidence of possible hospital-acquired suspected ADRs of around 16\%, 200 inpatients would suffice for a SE of 2.5\%; with 800 inpatients needed for the $95 \%$ CI to have a width of $5 \%{ }^{3}$ We found a substantially higher incidence of possible suspected ADRs (25\%; $194 / 762)$ so that, in practice, the same goal was met.

\section{Incidence of possible/probable hospital-acquired suspected ADRs}

Incidence was computed as the total number of patients who developed at least one new possible (or probable) hospital-acquired suspected ADR linked to the use of a drug initiated during the current hospitalisation expressed as a proportion of the total number of patients in the study cohort. We excluded all community-acquired suspected ADRs that existed at the time of hospital admission or emerged as new suspected ADRs during the current hospitalisation as a result of exposure to medication used preadmission.
Frequency of ADR-implicated drugs and hospital-acquired suspected ADRs

Proportions of drug classes most frequently implicated for suspected ADRs were expressed, at patient-level, as the number of patients who experienced an ADR linked to a named drug class divided by the total number of patients who experienced; (i) possible hospital-acquired suspected ADRs and (ii) probable hospital-acquired suspected ADRs. At ADR-level, the proportion of hospital-acquired suspected ADRs by drug class was expressed as a percentage of the total number of hospital-acquired suspected ADRs in the cohort, whereby a patient contributed one or more ADRs. Frequencies of possible hospital-acquired suspected ADRs in each drug class and for each individual drug were also reported.

\section{Risk factors for possible and probable hospital-acquired suspected ADRs}

To identify the risk factors for possible/probable hospital-acquired suspected ADR, we tested the joint effect of all potential risk factors using binary logistic regression: first on 'experienced at least one probable ADR', and subsequently on possible ADR. Results obtained for linearity were compared with those using categorisation by comparing the log-likelihoods for regressors in logistic regression for natural logarithm of the odds on having experienced possible or probable ADR. However, wide $95 \%$ CIs for the probable ADR model signalled over-fitting and so we simplified to six key explanatory variables: linear age, gender, number of conventional medicines $(\geq 6)$, Charlson's comorbidity index $(\geq 3)$, preadmission herbal medicine use and HIV-positive serostatus. Two additional explanatory variables (hospitalisation in previous 3 months and gynaecological ward) were tested in the possible $\mathrm{ADR}$ regression model. Prior to regression analysis, the missing-assigned approach was used to attribute low frequency missing data for categorical variables (use of herbal medicines and previous hospitalisation) to the 'no' stratum. Logistic regression models for possible/probable hospital-acquired ADRs were stratified by HIV serostatus (HIV-positive vs HIV-negative/unknown HIV serostatus) to assess for interaction. Results are reported as ORs with their corresponding 95\% CIs. Owing to the multiplicity of testing for interaction between HIV-positive serostatus and the six categorized explanatory variables, interaction needed to be significant at the $1 \%$ level (Bonferroni correction).

\section{Risk scores for predicting actual cases of possible and probable hospital-acquired ADRs}

Each patient's risk-score for developing a possible/probable hospital-acquired ADR was computed on the natural logarithmic scale using regression coefficients from the final logistic regression models for possible/probable hospital-acquired ADRs, see online supplementary appendix S1 for details of risk-score computation.

We used the risk-score extreme subsets (low-risk vs highrisk) to examine for qualitative differences between the 
predicted ADR cases in the low-risk and high-risk groups on characteristics which were not part of risk-score computation, namely implicated drug class, ward (for probable ADR only), number of working diagnoses per patient, number of hospital-acquired suspected ADRs per patient and nature of ADR, see online supplementary Appendix S1 for details of qualitative differences between the low-risk and high-risk ADR-patients.

\section{ETHICAL CLEARANCE}

Ethical approval for the study was obtained from the School of Medicine Research and Ethics Committee, Makerere University College of Health Sciences (REC REF No. 2011-113), the Mulago Hospital Research and Ethics Committee (MREC 253) and the Uganda National Council for Science and Technology (HS 1151).

\section{RESULTS}

Patient characteristics

Table 1 shows characteristics of the 762 inpatients in the study cohort. The median age of inpatients was 30 years
(IQR: 24-42 years) with a median length of hospital stay of 4 days (IQR: 3-6 days). Forty-two per cent of inpatients $(320 / 762)$ were on the IDGI ward and 30\% (232/ 762) were HIV-positive.

\section{Incidence of hospital-acquired suspected ADRs}

The incidence of possible hospital-acquired suspected ADRs was $25 \%(194 / 762 ; 95 \%$ CI: $22 \%$ to $29 \%): 85$ (44\%) of 194 patients experienced serious possible ADRs. The risk of probable ADRs was 11\% (87/762; 95\% CI: 9\% to $14 \%)$ : 40 (46\%) of 87 patients had serious probable ADRs. HIV-positive patients on ART had a significantly lower incidence of possible hospital-acquired ADRs (19\% vs $30 \% ; \mathrm{p}=0.048$ ) but no difference when probable ADRs were assessed ( $11 \%$ vs $13 \%$; $\mathrm{p}=0.770)$ (see table 1$)$.

\section{Frequency and characteristics of hospital-acquired suspected ADRs}

A total of 344 possible hospital-acquired suspected ADRs were experienced by 194 inpatients or 101 probable hospital-acquired suspected ADRs were encountered by 87 inpatients (see tables 2 and 3 ). Ten per cent

Table 1 Demographic and clinical characteristics of 762 hospitalised patients, Uganda, 2014

\begin{tabular}{|c|c|c|c|c|c|}
\hline \multirow[b]{3}{*}{ Characteristics } & \multicolumn{4}{|c|}{ Hospital-acquired ADRs } & \multirow[b]{3}{*}{ All patients } \\
\hline & \multicolumn{2}{|c|}{ Possible ADR } & \multicolumn{2}{|c|}{ Probable ADR } & \\
\hline & Yes & No & Yes & No & \\
\hline Number of patients & $194(25)^{\star}$ & $568(75)$ & $87(11)^{\star}$ & $675(89)$ & $762(100)$ \\
\hline Age in years (median and IQR) & $29(25-39)$ & $30(24-43)$ & $29(24-40)$ & $30(24-42)$ & $30(24-42)$ \\
\hline \multicolumn{6}{|l|}{ Gender } \\
\hline Male & $51(22)$ & $177(78)$ & $22(10)$ & $206(90)$ & $228[30]$ \\
\hline Female & $143(27)$ & $391(73)$ & $65(12)$ & $469(88)$ & $534[70]$ \\
\hline Length of stay in days (median and IQR) & $6(4-8)$ & $4(3-6)$ & $6(4-8)$ & $4(3-6)$ & $4(3-6)$ \\
\hline Patient-days of hospitalisation & 1230 & 2511 & 564 & 3177 & 3741 \\
\hline \multicolumn{6}{|l|}{ HIV-serostatus (\% of total) } \\
\hline Positive & $56(24)$ & $176(76)$ & $28(12)$ & $204(88)$ & $232[30]$ \\
\hline On antiretroviral therapy† & $23(19)$ & $99(81)$ & $14(11)$ & $108(89)$ & $122[53]$ \\
\hline Not on antiretroviral therapy† & 33 (30) & 77 (70) & $14(13)$ & $96(87)$ & $110[47]$ \\
\hline Negative & $98(29)$ & $242(71)$ & $38(11)$ & $302(89)$ & $340[45]$ \\
\hline Unknown & $40(21)$ & $150(79)$ & $21(11)$ & $169(89)$ & $190[25]$ \\
\hline \multicolumn{6}{|l|}{ Hospitalisation in previous 3 months } \\
\hline No & $125(23)$ & $407(77)$ & $54(10)$ & $478(90)$ & $532[70]$ \\
\hline Yes & $69(30)$ & $161(70)$ & $33(14)$ & $197(86)$ & $230[30]$ \\
\hline \multicolumn{6}{|c|}{ Use of herbal medicines in the 4 weeks prior hospitalisation } \\
\hline No & $127(23)$ & $428(77)$ & $52(9)$ & $503(91)$ & $555[73]$ \\
\hline Yes & $67(32)$ & $140(68)$ & $35(17)$ & $172(83)$ & $207[27]$ \\
\hline \multicolumn{6}{|l|}{ Ward } \\
\hline $\begin{array}{l}\text { Infectious diseases and gastrointestinal } \\
\text { illnesses }\end{array}$ & $58(18)$ & $262(82)$ & 30 ( 9$)$ & $290(91)$ & $320[42]$ \\
\hline Haematology, neurology and endocrinology & $21(18)$ & $96(82)$ & $11(9)$ & $106(91)$ & $117[15]$ \\
\hline Cardiovascular, pulmonology and nephrology & $49(37)$ & $85(63)$ & $21(16)$ & $113(84)$ & $134[18]$ \\
\hline Gynaecology & $66(36)$ & $125(64)$ & $25(13)$ & $166(87)$ & $191[25]$ \\
\hline \multicolumn{6}{|c|}{$\begin{array}{l}\text { Italics represents further stratification of data in the 'Positive' stratum under HIV-serostatus. } \\
\text { *Incidence of possible hospital-acquired ADRs was } 25 \% \text { (194/762; } 95 \% \text { Cl } 22 \% \text { to } 29 \%): 85(44 \%) \text { of } 194 \text { patients experienced serious } \\
\text { possible ADRs; and } 11 \% \text { ( } 87 / 762 ; 95 \% \text { CI } 9 \% \text { to } 14 \%) \text { probable ADRs: } 40(46 \%) \text { of } 87 \text { patients had serious probable ADRs. } \\
\text { †Test of significance for developing an ADR among HIV-positive patients using (vs not using) antiretroviral therapy; } \chi^{2}(\mathrm{df}=1)=3.93 ; p=0.048 \text { for } \\
\text { possible ADR and } \chi^{2}(\mathrm{df}=1)=0.09 ; p=0.770 \text { for probable ADR. } \\
\text { ( )=row \%; [ ]=column \%. } \\
\text { ADRs, adverse drug reactions. }\end{array}$} \\
\hline
\end{tabular}


Table 2 Drug classes most frequently ADR-implicated among the 194 inpatients with possible hospital-acquired ADRs and the 87 inpatients with probable hospital-acquired ADRs, Uganda, 2014

\begin{tabular}{|c|c|c|c|}
\hline \multirow[b]{2}{*}{ Drug class } & \multirow[b]{2}{*}{$\begin{array}{l}\text { All ADRs, } \\
\mathrm{n}(\%)\end{array}$} & \multicolumn{2}{|c|}{ Hospital-acquired ADRs, n (\%) } \\
\hline & & $\begin{array}{l}\text { Possible } \\
\text { ADR }\end{array}$ & $\begin{array}{l}\text { Probable } \\
\text { ADR }\end{array}$ \\
\hline \multicolumn{4}{|l|}{ Single drug class } \\
\hline Antibacterials (Antibact) only & $61(19)$ & $51(26)$ & $12(14)$ \\
\hline Antiretrovirals (ART) only & $38(12)$ & $0(0)$ & $0(0)$ \\
\hline Uterotonics only & $26(8)$ & $21(11)$ & $5(6)$ \\
\hline Cardiovascular (CVS) drugs only & $21(7)$ & $16(8)$ & $7(8)$ \\
\hline Antimalarials (Antimal) only & $19(6)$ & $12(6)$ & $9(10)$ \\
\hline Analgesics only & $12(4)$ & $10(5)$ & $7(8)$ \\
\hline Antituberculous (AntiTB) drugs only & $8(3)$ & $2(1)$ & $0(0)$ \\
\hline Blood only & $6(2)$ & $5(3)$ & $1(1)$ \\
\hline Hypoglycaemics only & $6(2)$ & $1(1)$ & $0(0)$ \\
\hline Antifungals only & $3(1)$ & $3(2)$ & $1(1)$ \\
\hline Herbal medicines only & $2(1)$ & $0(0)$ & $0(0)$ \\
\hline \multicolumn{4}{|l|}{ Two or more drug classes } \\
\hline Antibact and ART & $17(5)$ & $3(2)$ & $2(2)$ \\
\hline Antibact and analgesic & $13(4)$ & $12(6)$ & 7 (8) \\
\hline ART and AntiTBs & $5(2)$ & $1(1)$ & $1(1)$ \\
\hline ART+Antibact+AntiTB & $4(1)$ & $1(1)$ & $0(0)$ \\
\hline Antibact+AntiTB & $3(1)$ & $3(2)$ & $1(1)$ \\
\hline Central Nervous System & $3(1)$ & $3(2)$ & $3(3)$ \\
\hline Antibact+Uterotonic & $3(1)$ & $3(2)$ & $2(2)$ \\
\hline Antibact+Antimal & $2(1)$ & $2(1)$ & $2(2)$ \\
\hline ART and analgesic & $2(1)$ & $2(1)$ & $2(2)$ \\
\hline Other & $66(21)$ & 43 (22) & $25(29)$ \\
\hline Total & $320(100)$ & $194(100)$ & $87(100)$ \\
\hline
\end{tabular}

Table 3 System organ class distribution of 344 possible hospital-acquired ADRs in 194 inpatients and 101 probable hospital-acquired ADRs in 87 inpatients, Uganda, 2014

\begin{tabular}{lcc}
\hline sOC name & $\begin{array}{c}\text { Possible hospital-acquired } \\
\text { ADRs, } \mathbf{n} \text { (row \%) }\end{array}$ & $\begin{array}{c}\text { Probable hospital-acquired } \\
\text { ADRs, } \mathbf{n}(\text { row \%) }\end{array}$ \\
\hline Gastrointestinal disorders & $157(46)$ & $46(46)$ \\
Neurological disorders & $79(23)$ & $23(23)$ \\
Body-general disorders & $36(10)$ & $5(5)$ \\
Cardiovascular disorders & $25(7)$ & $10(10)$ \\
Vascular, bleeding and clotting disorders & $13(4)$ & $5(5)$ \\
Skin and appendages disorders & $8(2)$ & $0(0)$ \\
Others & $26(8)$ & $12(12)$ \\
Total & $344(100)$ & $101(100)$ \\
ADR, adverse drug reaction; SOC, system organ class. & &
\end{tabular}

(33/344) of possible hospital-acquired suspected ADRs were identified from laboratory and other objective investigations. Gastrointestinal $(46 \%)$ and neurological $(23 \%)$ disorders were the commonest system organ classes affected (see table 3). Fifty-five per cent (188/ 344) of possible hospital-acquired suspected ADRs were probably or definitely preventable, $13 \%$ (45/344) severe or life-threatening and 31\% (106/344) serious; none were fatal (see table 4). Frequencies of the possible hospital-acquired suspected ADRs, by drug class and individual pharmacological agents, are shown in table 5 .
Frequency of drugs implicated for hospital-acquired suspected ADRs

Possible ADRs linked to antibacterials-only accounted for the largest proportion $(26 \%, 51 / 194)$ of possible hospitalacquired ADRs attributed to a single drug class, at the patient level, followed by suspected ADRs linked to uterotonics-only $(11 \%, 21 / 194)$, cardiovascular drugs-only $(8 \%, 16 / 194)$, antimalarials-only $(6 \%, 12 / 194)$ and analgesics-only $(5 \%, 10 / 194)$, among others (see table 2$)$. Ceftriaxone (48/51), misoprostol (20/21), nifedipine $(7 / 16)$, quinine $(10 / 12)$ and tramadol $(7 / 10)$, 
Table 4 Causality, preventability, severity and seriousness of 344 hospital-acquired suspected ADRs experienced by 194 inpatients, Uganda, 2014

\begin{tabular}{|c|c|c|}
\hline Assessment & Category & $\begin{array}{l}\text { Hospital- } \\
\text { acquired ADRs } \\
(n, \%), N=344\end{array}$ \\
\hline \multicolumn{3}{|c|}{ Causality and preventability } \\
\hline \multirow[t]{3}{*}{ Causality } & Definite & $9(2)$ \\
\hline & Probable & $92(27)$ \\
\hline & Possible & $243(71)$ \\
\hline \multirow[t]{3}{*}{ Preventability } & Definitely preventable & $8(2)$ \\
\hline & Probably preventable & $180(52)$ \\
\hline & Not preventable & $156(45)$ \\
\hline \multicolumn{3}{|c|}{ Severity and seriousness } \\
\hline \multirow[t]{4}{*}{ Severity* } & Mild & $148(43)$ \\
\hline & Moderate & $151(44)$ \\
\hline & Severe & 42 (12) \\
\hline & Life-threatening & $3(1)$ \\
\hline \multirow[t]{6}{*}{ Serious } & Yes $^{\star}$ & $106(31)$ \\
\hline & $\begin{array}{l}\text { Required intervention } \\
\text { to prevent damage } \dagger\end{array}$ & $54(51)$ \\
\hline & $\begin{array}{l}\text { Caused or prolonged } \\
\text { hospitalisation } \dagger\end{array}$ & $30(28)$ \\
\hline & $\begin{array}{l}\text { Other medically } \\
\text { significant conditiont }\end{array}$ & $14(13)$ \\
\hline & Other & $8(8)$ \\
\hline & $\mathrm{No}^{*}$ & $238(69)$ \\
\hline
\end{tabular}

*Denominator used was the total number of hospital-acquired suspected ADRs, $n=344$.

†Denominator used was the number of serious hospital-acquired suspected ADRs, $\mathrm{n}=106$.

respectively, were the commonest individual pharmacological agents linked to possible ADRs in each of the above-mentioned drug classes. Table 2 also shows that no possible/ probable hospital-acquired suspected ADRs linked to antiretrovirals-only and/or herbal medicines-only were identified.

\section{Risk factors for possible/probable hospital-acquired suspected ADRs}

Treatment with six or more conventional medicines during hospitalisation (OR=2.31, 95\% CI 1.29 to 4.15$)$ and self-reported use of herbal medicines in the 4 weeks prior hospitalisation ( $\mathrm{OR}=1.96,95 \%$ CI: 1.22 to 3.13 ) were the risk factors for a probable hospital-acquired suspected ADR (see table 6).

Risk factors for a possible hospital-acquired suspected ADR were: treatment with six or more conventional medicines $(\mathrm{OR}=2.72,95 \%$ CI: 1.79 to 4.13$)$, self-reported use of herbal medicines in the 4 weeks prior hospitalisation $(\mathrm{OR}=1.68,95 \%$ CI: 1.16 to 2.43$)$, hospitalisation in the 3 months prior hospital admission ( $\mathrm{OR}=1.57,95 \%$ CI 1.09 to 2.26) and being on the gynaecological ward $(\mathrm{OR}=2.16,95 \%$ CI: 1.36 to 3.44 , see table 7$)$.

\section{Interaction between risk factors for possible} hospital-acquired suspected ADRs

Interaction was observed between HIV-positive serostatus and having a score of 3 or more on Charlson's comorbidity index in patients with and those without a possible hospital-acquired ADR. A Charlson's comorbidity index of 3 or more among the HIV-positive patients seemed to pose a risk $(\mathrm{OR}=1.9)$ for a possible hospital-acquired ADR, but was protective $(\mathrm{OR}=0.4)$ among the HIV-negative/unknown serostatus patients. The regression $\chi_{(\mathrm{df}=8)}^{2}=48.24$ for the model without the interaction term (Charlson's comorbidity index $\geq 3$ \& HIV-positive serostatus) was significantly lower than the $\chi_{(\mathrm{df}=9)}^{2}=53.99$ for the full model with the interaction term on 1-degree of freedom. However, the interaction was not significant at $\mathrm{p}<0.01$ as strict Bonferroni correction would have required.

\section{Qualitative differences between predicted ADR cases in the high-risk versus low-risk groups}

Suspected ADR cases in the high-risk (vs low-risk) groups implicated more drug classes (possible (18 vs 8 ) and probable (12 vs 7) ADRs), had more frequent occurrence of ADRs linked to cardiovascular drugs (possible ADRs: $(8 / 35)$ versus $(1 / 31))$ and were more common on the HNE ward (probable ADRs: (3/16) versus (0/14), see online supplementary appendices S1-S5).

\section{DISCUSSION}

\section{Incidence of hospital-acquired suspected ADRs}

One in four patients experienced at least one possible hospital-acquired suspected ADR during the current admission, which is higher than the ADR incidence reported in South Africa ${ }^{6}$ but similar to the incidence reported in the UK. ${ }^{3}$ The South African and UK studies estimated the incidence of hospital-acquired ADRs by including, as in our cohort of inpatients, all possible, prob$a b l e$ and definite ADRs. However, the South African study ${ }^{6}$ used the WHO-UMC criteria ${ }^{22}$ for ADR causality assessment rather than the Naranjo algorithm, ${ }^{15}$ as in our cohort and the UK study. Poor agreement between the WHO-UMC criteria and Naranjo algorithm is reported in the causality assessment of 913 ADRs by the same evaluator at a tertiary care hospital in India, ${ }^{23}$ which might partly explain the observed differences in the ADR incidence estimates: however, good agreement between the two causality assessment tools is reported in an assessment of 200 ADR forms submitted to an Indian pharmacovigilance centre. ${ }^{24}$ The comparable ADR incidences in our cohort and the UK setting should be interpreted cautiously, however, because the UK study used the Edwards and Aronson ADR definition while we used the WHO definition; $;^{3131425}$ and we had a smaller amount of laboratory data on ADR-markers, which might have resulted in ADR underestimation in our setting. The incidence of probable hospital-acquired suspected ADRs was one in nine inpatients, which is half our estimate for a possible hospital-acquired suspected ADR. Incidence estimates of probable ADRs are less likely to include adverse reactions caused by underlying disease. ${ }^{26}$ However, ascertaining ADR causality of 


\begin{tabular}{llll}
\hline $\begin{array}{l}\text { Pharmacological } \\
\text { drug class }\end{array}$ & $\begin{array}{l}\text { Number of } \\
\text { hospital-acquired } \\
\text { ADRs, } n(\%)^{*}\end{array}$ & $\begin{array}{l}\text { Rank by } \\
\text { causative } \\
\text { drug }\end{array}$ & $\begin{array}{l}\text { Rank by } \\
\text { frequency } \\
\text { of use }\end{array}$ \\
\hline
\end{tabular}

Antibacterials

$150(44)$

1

Ceftriaxone (93), metronidazole (42), levofloxacin (15), ciprofloxacin (11), azithromycin (6), erythromycin (6), amoxicillin (3), co-trimoxazole (2), ampicillin (2), cloxacillin (1), gentamicin (1), clavulanic acid (1)

\begin{tabular}{|c|c|c|c|c|}
\hline Uterotonics & $43(13)$ & 2 & 3 & Misoprostol (36), oxytocin (10) \\
\hline $\begin{array}{l}\text { Cardiovascular } \\
\text { drugs }\end{array}$ & $39(11)$ & 3 & 4 & $\begin{array}{l}\text { Captopril (14), carvedilol (11), nifedipine (11), } \\
\text { frusemide (10), hydralazine (5), digoxin (3), } \\
\text { amlodipine (3), labetalol (2), cardiac aspirin (1), } \\
\text { lisinopril (1), propranolol (1) }\end{array}$ \\
\hline Analgesics & $36(10)$ & 4 & 2 & $\begin{array}{l}\text { Tramadol (19), diclofenac (8), morphine (4), codeine } \\
\text { (1), fentanyl (1) ibuprofen (1), paracetamol (1) }\end{array}$ \\
\hline Antimalarials & $26(8)$ & 5 & 5 & $\begin{array}{l}\text { Quinine (22), artesunate (5), artemether ( } 3 \text { ), } \\
\text { lumefantrine (3) }\end{array}$ \\
\hline $\begin{array}{l}\text { Central nervous } \\
\text { system drugs }\end{array}$ & $18(5)$ & 6 & 6 & $\begin{array}{l}\text { Haloperidol (10), diazepam (3), phenytoin (2), } \\
\text { benztropine (1), lignocaine (1), metoclopramide (1), } \\
\text { atropine (1) }\end{array}$ \\
\hline $\begin{array}{l}\text { Antituberculous } \\
\text { drugs }\end{array}$ & $15(4)$ & 7 & 7 & $\begin{array}{l}\text { Isoniazid (14), pyrazinamide (14), rifampicin (13), } \\
\text { ethambutol (10) }\end{array}$ \\
\hline
\end{tabular}

drugs

\section{Hospital-acquired ADRs (number of ADRs)}

Vomiting (32), dizziness (19), fever (16), nausea (15), appetite loss (14), headache (11), dizziness (8), diarrhoea (8), pruritus (6), abdominal pain (6), malaise (4), diarrhoea (4), dizziness (3), epigastric pain (3), constipation (2), skin rash (2), tachycardia (2), flatulence (1), jaundice (1), decreased urine output (1), oral sores (1), blurred vision (1), dyspepsia (1), peripheral neuropathy (1), abdominal discomfort (1), convulsions (1), paraesthesia (1), hypertension (1), palpitations (1)

Lower abdominal pain (13), vaginal bleeding (11), headache (5), diarrhoea (4), dizziness (3), vomiting (2), malaise (1), palpitations (1), back pain (1), raised pulse (1), nausea (1)

Headache (8), diarrhoea (3), dizziness (3), palpitations (3), vomiting (3), epigastric pain (3), dry cough (2), abdominal pain (2), oedema (2), joint pain (1), blurred vision (1), dysuria (1), nausea (1) constipation (1), low diastolic blood pressure (1), fever (1), paraesthesia (1), burning sensation (1), malaise (1), constipation (1), orthostatic hypotension (1), hypovolaemia (1)

Vomiting (11), dizziness (6), constipation (5), epigastric pain (4), nausea (3), headache (2), tachycardia (1), palpitations (1), diarrhoea (1) hypertension (1), abdominal pain (1), pruritus (1) Dizziness (4), vomiting (4), tinnitus (3), headache (3), nausea (2), vomiting (2), palpitations (1), taste disturbance (1), appetite loss (1), raised pulse (1), epigastric pain (1), diarrhoea (1), blurred vision (1), vaginal bleeding (1), lower abdominal pain (1), dysuria (1)

Dizziness (3), drowsiness (2), poor orientation to time and place (1), uncoordinated movement (1), blurred vision (1), appetite loss (1), hypotension (1) stiff neck (1), swollen tongue (1), fever (1), tremors (1), hypertension (1), swollen lips (1), malaise (1), vomiting (1), paraesthesia (1), headache (1)

Vomiting (3), diarrhoea (2), appetite loss (2), yellow eyes (1), nausea (1), fever (2), abdominal discomfort (1), paraesthesia (1), shortness of breath (1), dizziness (1) 


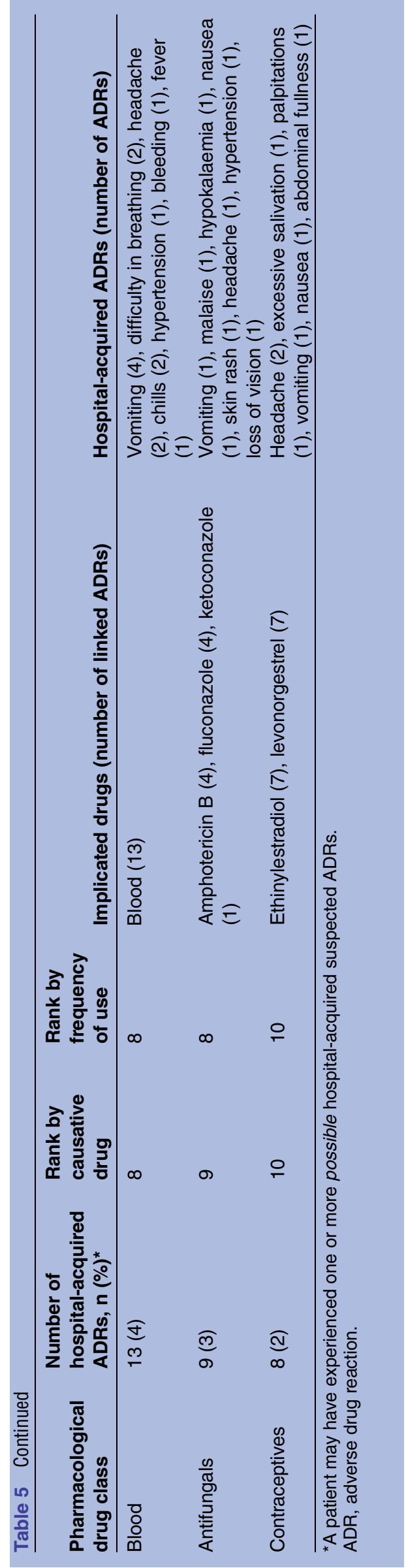

implicated drugs can be a challenge in a cohort of inpatients with multiple comorbidities, extensive preadmission medication exposure and concomitant medications. Moreover, the Naranjo algorithm is designed to assess ADR causality of a single drug and does not take into account drug-drug interactions. ${ }^{15}{ }^{24}$ By comparison, the median incidence estimate of hospital-acquired ADRs in European inpatients is 1 in 10 , as assessed in a recent systematic review of 13 studies. A variety of ADR causality assessment methods were used, and the majority of the studies did not differentiate between possible or probable ADRs: ${ }^{5}$ of the three studies which did, their reported possible ADR incidence estimates were either lower than $(8.4 \%),{ }^{27}$ similar to $(16 \%)^{3}$ or higher than $(38 \%)^{4}$ ours.

\section{Serious hospital-acquired suspected ADRs}

About half the inpatients with hospital-acquired suspected ADRs encountered serious ADRs, which highlights the substantial contribution of these ADRs to the patients' morbidity while in hospital. Our estimate of serious possible hospital-acquired suspected ADRs (11\%, $85 / 762$ ) is higher than the $2.1 \%$ reported in a meta-analysis of 39 American studies. ${ }^{28}$ However, none of the serious ADRs in our cohort were fatal. At least two to three deaths would have been expected among the 762 inpatients based on the ADR death estimates in the USA $(0.32 \%)$ and UK $(0.42 \%)$; which may be happenchance given the small sample size of our cohort compared with the two studies conducted in the western world. $^{3} 28$

\section{Implicated drug classes}

Previous research among medical inpatients in sub-Saharan Africa documented antibiotics ${ }^{6}$ and antimalarials, mostly quinine ${ }^{8}$ as the leading causes of hospital-acquired ADRs. A recent survey of Ugandan healthcare professionals, who provided descriptions of ADRs they had encountered in the previous monththough of community-acquired and hospital-acquired ADRs, also ranked antibiotics and antimalarials (particularly quinine) among the most commonly implicated drugs. ${ }^{29}{ }^{30}$ Our prospective cohort also studied gynaecological inpatients and highlights the high burden of hospital-acquired ADRs linked to uterotonics-mostly misoprostol. Cardiovascular drugs contribute frequently to hospital-acquired ADRs in the western world ${ }^{31}$ and to community-acquired ADRs in South Africa. ${ }^{6}$ We document the frequent occurrence of hospital-acquired ADRs linked to cardiovascular drugs in our cohort of inpatients in a sub-Saharan African setting.

No hospital-acquired suspected ADRs linked to antiretrovirals-only and/or herbal medicines-only were identified: probably because most patients who received ART had initiated the ART prior to the current hospital admission, and because we measured self-reported herbal medicine use during the 4 weeks prior to the current hospitalisation. 
Table 6 Risk factors for probable hospital-acquired suspected ADRs in 87 of 762 inpatients, Uganda, 2014

\begin{tabular}{|c|c|c|c|c|c|c|c|c|c|}
\hline \multirow[b]{2}{*}{ Characteristics } & \multicolumn{2}{|c|}{ Probable ADR, n (\%) } & \multicolumn{3}{|c|}{ Crude analysis } & \multicolumn{4}{|c|}{ Adjusted analysis } \\
\hline & Yes & No & $\overline{\text { OR }}$ & 95\% Cl for OR & p Value & $\beta$-adj & OR & 95\% Cl for OR & p Value \\
\hline \multicolumn{10}{|l|}{ Gender } \\
\hline Male & $22(10)$ & $206(90)$ & 1.0 & & & & 1.00 & & \\
\hline Female & $65(12)$ & $469(88)$ & 1.3 & 0.78 to 2.16 & 0.317 & 0.291 & 1.34 & 0.79 to 2.25 & 0.273 \\
\hline Age: mean (SD) & $34.6(15.8)$ & $34.8(14.7)$ & 0.97 & 0.98 to 1.01 & 0.888 & -0.010 & 1.01 & 0.97 to 1.01 & 0.269 \\
\hline \multicolumn{10}{|c|}{ Number of conventional medicines } \\
\hline Five or less & $16(7)$ & $228(93)$ & 1.0 & & & & 1.00 & & \\
\hline Six or more & $71(14)$ & $447(86)$ & 2.3 & 1.29 to 3.98 & 0.005 & 0.838 & 2.31 & 1.29 to 4.15 & 0.005 \\
\hline \multicolumn{10}{|c|}{ Use of herbal medicines in the 4 weeks prior hospitalisation } \\
\hline No & $52(9)$ & $503(91)$ & 1.0 & & & & 1.00 & & \\
\hline Yes & $35(17)$ & $172(83)$ & 2.0 & 1.24 to 3.12 & 0.004 & 0.673 & 1.96 & 1.22 to 3.13 & 0.005 \\
\hline \multicolumn{10}{|l|}{ HIV-positive } \\
\hline No or unknown & $59(11)$ & $471(89)$ & 1.0 & & & & 1.00 & & \\
\hline Yes & $28(12)$ & 204 (88) & 1.1 & 0.68 to 1.77 & 0.708 & 0.317 & 0.73 & 0.41 to 1.31 & 0.288 \\
\hline \multicolumn{10}{|c|}{ Charlson's comorbidity index } \\
\hline Two or fewer & $60(11)$ & $507(89)$ & 1.0 & & & & 1.00 & & \\
\hline Three or more & $27(14)$ & $168(86)$ & 1.4 & 0.83 to 2.21 & 0.218 & 0.505 & 1.66 & 0.88 to 3.13 & 0.119 \\
\hline Intercept & & & & & & -2.807 & 0.06 & 0.03 to 0.14 & \\
\hline
\end{tabular}

Table 7 Risk factors for possible hospital-acquired suspected ADRs in 194 of 762 inpatients, Uganda, 2014

\begin{tabular}{|c|c|c|c|c|c|c|c|c|c|}
\hline \multirow[b]{2}{*}{ Characteristics } & \multicolumn{2}{|c|}{ Possible ADR, n (\%) } & \multicolumn{3}{|c|}{ Crude analysis } & \multirow[b]{2}{*}{$\beta$-adj } & \multicolumn{3}{|c|}{ Adjusted analysis } \\
\hline & Yes & No & $\overline{\text { OR }}$ & $95 \% \mathrm{Cl}$ for OR & p Value & & $\overline{\text { OR }}$ & 95\% Cl for OR & p Value \\
\hline \multicolumn{10}{|l|}{ Gender } \\
\hline Male & $51(22)$ & $177(78)$ & 1.0 & & & & 1.01 & & \\
\hline Female & $143(27)$ & $391(73)$ & 1.3 & 0.88 to 1.83 & 0.201 & 0.011 & 1.00 & 0.67 to 1.53 & 0.959 \\
\hline Age: mean (SD) & $33.5(13.6)$ & $35.3(15.1)$ & 1.0 & 0.98 to 1.00 & 0.151 & -0.0006 & 1.00 & 0.98 to 1.01 & 0.933 \\
\hline \multicolumn{10}{|c|}{ Number of conventional medicines } \\
\hline Five or less & $39(16)$ & $205(84)$ & 1.0 & & & & 1.00 & & \\
\hline Six or more & $155(30)$ & $363(70)$ & 2.2 & 1.52 to 3.32 & $<0.001$ & 1.001 & 2.72 & 1.79 to 4.13 & $<0.001$ \\
\hline \multicolumn{10}{|c|}{ Use of herbal medicines in the 4 weeks prior hospitalisation } \\
\hline No & $127(23)$ & $428(77)$ & 1.0 & & & & 1.00 & & \\
\hline Yes & 67 (32) & $140(68)$ & 1.6 & 1.13 to 2.29 & 0.008 & 0.519 & 1.68 & 1.16 to 2.43 & 0.006 \\
\hline \multicolumn{10}{|l|}{ HIV-positive } \\
\hline No/unknown & $138(26)$ & $392(74)$ & 1.0 & & & & 1.00 & & \\
\hline Yes & $56(24)$ & $176(76)$ & 0.9 & 0.63 to 1.29 & 0.580 & -0.589 & 0.55 & 0.31 to 0.99 & 0.045 \\
\hline \multicolumn{10}{|c|}{ Charlson's comorbidity index } \\
\hline Two or less & $147(26)$ & $420(74)$ & 1.0 & & & & 1.00 & & \\
\hline Three or more & $47(24)$ & $148(76)$ & 0.9 & 0.62 to 1.32 & 0.614 & -0.613 & 0.54 & 0.24 to 1.24 & 0.146 \\
\hline \multicolumn{10}{|c|}{ Interaction: Charlson's index $\geq 3$ \& HIV+status } \\
\hline No interaction & $157(25)$ & $472(75)$ & 1.0 & & & & 1.00 & & \\
\hline Interaction & $37(28)$ & $96(72)$ & 1.2 & 0.76 to 1.76 & 0.492 & 1.235 & 3.44 & 1.22 to 9.71 & 0.020 \\
\hline \multicolumn{10}{|c|}{ Hospitalisation in past 3 months } \\
\hline No & $125(24)$ & $407(76)$ & 1.0 & & & & 1.00 & & \\
\hline Yes & $69(30)$ & $161(70)$ & 1.4 & 0.99 to 1.97 & 0.059 & 0.448 & 1.57 & 1.09 to 2.26 & 0.016 \\
\hline \multicolumn{10}{|c|}{ Gynaecological ward } \\
\hline No & $128(22)$ & $443(78)$ & 1.0 & & & & 1.00 & & \\
\hline Yes & $66(35)$ & $125(65)$ & 1.8 & 1.28 to 2.61 & 0.001 & 0.771 & 2.16 & 1.36 to 3.44 & 0.001 \\
\hline Intercept & - & - & & & & -2.19 & 0.11 & 0.06 to 0.23 & \\
\hline
\end{tabular}

Risk factors for hospital-acquired suspected ADRs

Given the complexity of confirming ADR causality of implicated drugs among our study inpatients, most of whom had multiple prior and current drug exposures, we undertook sensitivity analyses to determine the risk factors for experiencing at least one probable hospital- 
acquired suspected ADR; and separately for a possible hospital-acquired suspected ADR.

Patients who had used herbal medicines in the 4 weeks preadmission were at a higher risk of developing a possible/probable hospital-acquired suspected ADR. Previous research in Uganda has associated the use of herbal medicines, particularly traditional herbal medicines, with the occurrence of liver disease ${ }^{9}$ and possibly with defaulting on $\mathrm{ART}^{32}$ Drug interactions between western conventional and herbal medicines, if concurrently used, might moderate the occurrence of ADRs. ${ }^{33}$ On the other hand, prehospital use of herbal medicines might delay hospitalisation and resolution of the problem(s) that patients attempt to resolve by the use of the herbal medicines. ${ }^{34}$

The use of several conventional medicines is a known risk factor for ADRs. ${ }^{4} 35$ The ADRs may arise from drug interactions attributable to synergism. ${ }^{36}$ Patients who receive large numbers of medicines may need to take even more medications to treat ADRs of already administered medicines ${ }^{36}$ such as the prescription of bisacodyl to treat morphine-linked constipation. ${ }^{37}$ Hospitalisation in the previous 3 months prior to the present admission was an independent risk factor for possible ADR, but not probable $\mathrm{ADR}$, and might relate to ADR-prone patients with previous drug exposures and/or chronic disease state(s).

The risk of developing a possible hospital-acquired suspected ADR was twice as high on the GYN ward when compared with the three medical wards probably due to the exclusive use of uterotonics (mainly misoprostol) on the GYN ward, which ranked second in the group of pharmacological drug classes most frequently linked to possible ADRs.

The observed interaction between HIV-positive serostatus and Charlson's comorbidity index might be explained by the high score of 6 in the index assigned to HIV/AIDS. ${ }^{38}$ Thus, Charlson's comorbidity index might require adaptation for settings with a high burden of HIV/AIDS. Researchers in a high HIV/AIDS prevalence setting in South Africa have used the tool after excluding the score for HIV/AIDS; however, it is not known whether their revision was validated. ${ }^{39}$

\section{Use of risk scores to differentiate the characteristics of low-risk and high-risk ADR cases}

We identified qualitative, though weak, differences between the low-risk and high-risk ADR cases by implicated drug class, nature of ADR and ward (for probable ADR only), but not by number of working diagnoses or number of ADRs per patient. The small number of events, especially for probable ADRs, or the more likely important influence of other unmeasured clinical or organisational factors (eg, medication errors with respect to the ADRs) might partly explain the weak prediction of the qualitative differences between low-risk and high-risk groups of ADR cases on characteristics not modelled in the logistic regression.
Low uptake of risk prediction compromises the safety of clinical care. Risk scores can be useful tools to screen for patients at high risk for ADRs, who would need more careful selection and close monitoring of their medications. ${ }^{40}$ Obtaining a good ADR risk-prediction model requires four stages, namely development and validation, and impact and implementation assessment. Our ADR risk-prediction models were not validated due to the small number of probable ADR events among the inpatients. The risk-prediction models, however, delivered in differentiating between low-risk and high-risk ADR-patients on characteristics not included in riskscore computation. Nonetheless, we acknowledge that these models should be validated, in our setting, using large-scale or periodic studies.

\section{Study limitations}

The covariate 'number of conventional medicines', which accounted for the total number of western conventional medicines administered during hospitalisation, has the drawback that some conventional medicines may have been received after the occurrence of a suspected ADR. Partly for this reason, we categorised number of medicines to indicate simply if the patient had received six or more medicines, that is, many. Except for the risk factor 'number of conventional medicines', all the other tested potential risk factors (age, gender, HIV serostatus, history of previous hospital admission, comorbidities and self-reported use of herbal medicines) were known to have preceded the occurrence of a possible/probable ADR. Arguably, Cox proportional hazards with timedependent covariates to track the daily changes in the number of medicines administered prior to possible/probable ADR might have been a better method of analysis. However, time to first possible/probable ADR in days for most cases was rather short and accurate tracking of diverse coadministered medicines before and after ADR recognition was unlikely, even if practicable, to have yielded commensurate insights. Clinical examination was the main method used to identify suspected ADRs due to limitations in timely availability of laboratory investigation results.

\section{CONCLUSIONS}

The risk of developing a hospital-acquired suspected ADR was high. Preadmission use of herbal medicines and treatment with six or more conventional medicines during hospitalisation were the common risk factors for possible/ probable hospital-acquired suspected ADRs. The risk scores were predictive of qualitative differences between low-risk and high-risk groups of ADR cases on characteristics not modelled in the regression analyses and should be validated and assessed for their usefulness and acceptance in routine clinical practice in our setting.

Contributors RK conceived of the study and drafted the manuscript and, in conjunction with SMB, participated in its design, implementation, statistical 
analysis and drawing of inferences. CK participated in study design and, together with SMB, took part in the manuscript writing process. All authors approved the final manuscript.

Funding RK gratefully acknowledges funding support provided by the Training Health Researchers into Vocational Excellence (THRiVE) in East Africa grant number 087540, funded by the Wellcome Trust; and an African Doctoral Dissertation Research Fellowship (ADDRF) award 2013-2015 ADF 006 offered by the African Population and Health Research Centre (APHRC) in partnership with the International Development Research Centre (IDRC). In UK, SMB is funded by Medical Research Council programme number, MC_U105260794.

Disclaimer The work here reported is solely the responsibility of the authors and does not necessarily represent the official views of the supporting offices. The funders had no role in the decisions on what and where to publish.

\section{Competing interests SMB holds GSK shares.}

Ethics approval Ethical approval for the study was obtained from the School of Medicine Research and Ethics Committee, Makerere University College of Health Sciences (REC REF No. 2011-113), the Mulago Hospital Research and Ethics Committee (MREC 253) and the Uganda National Council for Science and Technology (HS 1151).

Provenance and peer review Not commissioned; externally peer reviewed.

Data sharing statement The data are available from the lead author, RK, by email request to kiguba@gmail.com

Open Access This is an Open Access article distributed in accordance with the terms of the Creative Commons Attribution (CC BY 4.0) license, which permits others to distribute, remix, adapt and build upon this work, for commercial use, provided the original work is properly cited. See: http:// creativecommons.org/licenses/by/4.0/

\section{REFERENCES}

1. Jemal $A$, Ward $E$, Hao $Y$, et al. Trends in the leading causes of death in the United States, 1970-2002. JAMA 2005;294:1255-9.

2. Wester K, Jonsson AK, Spigset $\mathrm{O}$, et al. Incidence of fatal adverse drug reactions: a population based study. $\mathrm{Br} J$ Clin Pharmacol 2008;65:573-9.

3. Davies EC, Green CF, Taylor S, et al. Adverse drug reactions in hospital in-patients: a prospective analysis of 3695 patient-episodes. PLoS One 2009;4:e4439.

4. Zopf $Y$, Rabe C, Neubert A, et al. Risk factors associated with adverse drug reactions following hospital admission. Drug Saf 2008;31:789-98.

5. Bouvy JC, De Bruin ML, Koopmanschap MA. Epidemiology of adverse drug reactions in Europe: a review of recent observational studies. Drug Saf 2015;38:437-53.

6. Mehta U, Durrheim DN, Blockman M, et al. Adverse drug reactions in adult medical inpatients in a South African hospital serving a community with a high HIV/AIDS prevalence: prospective observational study. Br J Clin Pharmacol 2008;65:396-406.

7. Alomar MJ. Factors affecting the development of adverse drug reactions (Review article). Saudi Pharm J 2014;22:83-94.

8. Tumwikirize WA, Ogwal-Okeng JW, Vernby A, et al. Adverse drug reactions in patients admitted on internal medicine wards in a distric and regional hospital in Uganda. Afr Health Sci 2011;11:72-8.

9. Auerbach BJ, Reynolds SJ, Lamorde M, et al. Traditional herbal medicine use associated with liver fibrosis in Rural Rakai, Uganda. PLoS One 2012;7:e41737.

10. Tangiisuran B, Scutt G, Stevenson J, et al. Development and validation of a risk model for predicting adverse drug reactions in older people during hospital stay: Brighton Adverse Drug Reactions Risk (BADRI) Model. PLoS One 2014;9:e111254.

11. Toll DB, Janssen $\mathrm{KJ}$, Vergouwe $\mathrm{Y}$, et al. Validation, updating and impact of clinical prediction rules: a review. J Clin Epidemiol 2008;61:1085-94.

12. Kiguba R, Karamagi C, Bird SM. Extensive antibiotic prescription rate among hospitalized patients in Uganda: but with frequent missed-dose days. J Antimicrob Chemother 2016;71:1697-706.

13. World Health Organization (WHO)-Uppsala Monitoring Centre (UMC). Glossary of terms used in Pharmacovigilance. 2011 (cited 13 March 2015). http://who-umc.org/Graphics/24729.pdf

14. WHO. International Drug Monitoring - The Role of National Centres. Technical Report Series No 498. 1972 (cited 15 September 2015). http://apps.who.int/iris/bitstream/10665/40968/1/WHO_TRS_498.pdf.
15. Naranjo CA, Busto U, Sellers EM, et al. A method for estimating the probability of adverse drug reactions. Clin Pharmacol Ther 1981;30:239-45.

16. WHO-UMC. Glossary of terms used in Pharmacovigilance. 2011 (cited 13 March 2015). http://who-umc.org/Graphics/24729.pdf

17. Lau PM, Stewart K, Dooley MJ. Comment: hospital admissions resulting from preventable adverse drug reactions. Ann Pharmacother 2003;37:303-4. Author reply 4-5.

18. Schumock GT, Thornton JP. Focusing on the preventability of adverse drug reactions. Hosp Pharm 1992;27:538.

19. US Department of Health and Human Services, National Institutes of Health, National Institute of Allergy and Infectious Diseases. Division of AIDS (DAIDS) Table for Grading the Severity of Adult and Paediatric Adverse Events. 2004 Clarification dated August 2009 (cited 14 March 2015); version 1.0-December 2004. http://rsc. tech-res.com/safetyandpharmacovigilance/gradingtables.aspx

20. WHO-UMC. Safety monitoring of medicinal products: guidelines for setting up and running a pharmacovigilance centre, 2000 (cited 15 January 2015). http://apps.who.int/medicinedocs/en/p/printable.html

21. Rozich JD, Haraden CR, Resar RK. Adverse drug event trigger tool: a practical methodology for measuring medication related harm. Qual Saf Health Care 2003;12:194-200.

22. WHO-UMC. The use of the WHO-UMC system for standardised case causality assessment (cited 20 September 2011). http:// who-umc.org/Graphics/24734.pdf

23. Belhekar MN, Taur SR, Munshi RP. A study of agreement between the Naranjo algorithm and WHO-UMC criteria for causality assessment of adverse drug reactions. Ind $\mathrm{J}$ Pharmacol 2014:46:117-20.

24. Mittal N, Gupta MC. Comparison of agreement and rational uses of the WHO and Naranjo adverse event causality assessment tools. $J$ Pharmacol Pharmacother 2015;6:91-3.

25. Edwards IR, Aronson JK. Adverse drug reactions: definitions, diagnosis, and management. Lancet 2000;356:1255-9.

26. Thiesen S, Conroy EJ, Bellis JR, et al. Incidence, characteristics and risk factors of adverse drug reactions in hospitalized children-a prospective observational cohort study of 6,601 admissions. BMC Med 2013;11:237

27. Thuermann PA, Windecker R, Steffen J, et al. Detection of adverse drug reactions in a neurological department: comparison between intensified surveillance and a computer-assisted approach. Drug Saf 2002;10:713-24.

28. Lazarou J, Pomeranz BH, Corey PN. Incidence of adverse drug reactions in hospitalized patients: a meta-analysis of prospective studies. JAMA 1998;279:1200-5.

29. Kiguba R, Karamagi C, Waako $P$, et al. Recognition and reporting of suspected adverse drug reactions by surveyed healthcare professionals in Uganda: key determinants. BMJ Open 2014;4 e005869.

30. Kiguba $\mathrm{R}$, Karamagi $\mathrm{C}$, Waako $\mathrm{P}$, et al. Rare, serious, and comprehensively described suspected adverse drug reactions reported by surveyed healthcare professionals in Uganda. PLOS One 2015;10:e0123974.

31. Weiss AJ, Elixhauser A, Bae J, et al. Origin of adverse drug events in US hospitals, 2011: Statistical Brief \#158. Healthcare Cost and Utilization Project (HCUP) statistical briefs. Rockville (MD), 2006.

32. Kiguba R, Byakika-Tusiime J, Karamagi C, et al. Discontinuation and modification of highly active antiretroviral therapy in HIV-infected Ugandans: prevalence and associated factors. J Acquir Immune Defic Syndr 2007;45:218-23.

33. Fugh-Berman A. Herb-drug interactions. Lancet 2000;355:134-8.

34. Cawich SO, Harnarayan P, Islam S, et al. Adverse events in diabetic foot infections: a case control study comparing early versus delayed medical treatment after home remedies. Risk Manag Healthc Policy 2014;7:239-43.

35. Macedo AF, Alves C, Craveiro N, et al. Multiple drug exposure as a risk factor for the seriousness of adverse drug reactions. J Nurs Manag 2011;19:395-9.

36. Harugeri A, Parthasarathi $\mathrm{G}$, Ramesh $\mathrm{M}$, et al. Frequency and nature of adverse drug reactions in elderly in-patients of two Indian medical college hospitals. J Postgrad Med 2011;57:189-95.

37. British National Formulary. London: BMJ Group and Pharmaceutical Press, 2014

38. Charlson ME, Pompei P, Ales KL, et al. A new method of classifying prognostic comorbidity in longitudinal studies: development and validation. J Chronic Dis 1987;40:373-83.

39. Mouton JP, Mehta U, Parrish AG, et al. Mortality from adverse drug reactions in adult medical inpatients at four hospitals in South Africa: a cross-sectional survey. Br J Clin Pharmacol 2015;80:818-26.

40. Yourman LC, Lee SJ, Schonberg MA, et al. Prognostic indices for older adults. A systematic review. JAMA 2012;307:182-92. 